\title{
Polymorphisms of pfcrt, pfmdr1, and K13- propeller genes in imported falciparum malaria isolates from Africa in Guizhou province, China
}

Danya She ${ }^{1,2+}$, Zhengyan Wang ${ }^{1+}$, Qiuguo Liang ${ }^{1}$, Lidan Lu' ${ }^{2}$, Yuting Huang ${ }^{2}$, Ke Zhang ${ }^{1}$, Dong $\mathrm{An}^{2}$ and Jiahong $\mathrm{Wu}^{1 *}$

\begin{abstract}
Background: Imported falciparum malaria from Africa has become a key public health challenge in Guizhou Province since 2012. Understanding the polymorphisms of molecular markers of drug resistance can guide selection of antimalarial drugs for the treatment of malaria. This study was aimed to analyze the polymorphisms of pfcrt, pfmdr1, and K13-propeller among imported falciparum malaria cases in Guizhou Province, China.

Method: Fifty-five imported falciparum malaria cases in Guizhou Province during 2012-2016 were included in this study. Their demographic information and filter paper blood samples were collected. Genomic DNA of Plasmodium falciparum was extracted from the blood samples, and polymorphisms of pfcrt, pfmdr1, and K13-propeller were analyzed with nested PCR amplification followed by sequencing. Data were analyzed with the SPSS17.0 software.

Results: The prevalence of pfcrt K76T, pfmdr1 N86Y, and pfmdr1 Y184F mutation was 56.6, 22.2, and 72.2\%, respectively, in imported falciparum malaria cases in Guizhou Province. We detected two mutant haplotypes of pfcrt, IET and MNT, with IET being more commonly found (54.7\%), and five mutant haplotypes of pfmdr1, of which NFD was the most frequent (53.7\%). There were totally 10 combined haplotypes of pfcrt and pfmdr1, of which the haplotype IETNFD possessed a predominance of 28.8\%. In addition, three nonsynonymous mutations (S459T, C469F, and V692L) and two synonymous mutations (R471R and V589V) were detected in K13-propeller, all having prevalence less than 6.0\%. In particular, a candidate K13 resistance mutation, C469F, was identified for the first time from Democratic Republic of the Congo with the prevalence of 2.0\%.

Conclusions: The high prevalence of IET haplotype of pfcrt and NFD haplotype of pfmdr1 suggests the presence of chloroquine, artemether/lumefantrine, and dihydroartemisinin/piperaquine resistance in these cases. Therefore cautions should be made to artemisinin therapy for P. falciparum in Africa. Continuous monitoring of anti-malarial drug efficacy in imported malaria cases is helpful for optimizing antimalarial drug therapy in Guizhou Province, China.
\end{abstract}

Keywords: Plasmodium falciparum, Antimalarial drugs, Resistance, Polymorphism, Haplotype

\footnotetext{
* Correspondence: jiahongwu2008@hotmail.com

${ }^{\dagger}$ Danya She and Zhengyan Wang contributed equally to this work.

'Key Laboratory of Environmental Pollution Monitoring and Disease Control, Ministry of Education, Guizhou Medical University; Department of

Parasitology; Provincial Key Laboratory of Modern Pathogen Biology, Guizhou Medical University, Guiyang 550025, China

Full list of author information is available at the end of the article
}

(c) The Author(s). 2020 Open Access This article is licensed under a Creative Commons Attribution 4.0 International License, which permits use, sharing, adaptation, distribution and reproduction in any medium or format, as long as you give appropriate credit to the original author(s) and the source, provide a link to the Creative Commons licence, and indicate if changes were made. The images or other third party material in this article are included in the article's Creative Commons licence, unless indicated otherwise in a credit line to the material. If material is not included in the article's Creative Commons licence and your intended use is not permitted by statutory regulation or exceeds the permitted use, you will need to obtain permission directly from the copyright holder. To view a copy of this licence, visit http://creativecommons.org/licenses/by/4.0/ The Creative Commons Public Domain Dedication waiver (http://creativecommons.org/publicdomain/zero/1.0/) applies to the data made available in this article, unless otherwise stated in a credit line to the data. 


\section{Background}

Malaria remains an important public health problem in tropical and sub-tropical countries. It has been estimated that there were 216 million clinical cases of malaria and approximately 445,000 deaths in 2016, of which nearly 92\% occurred in Africa, according to the World Health Organization (WHO) data [1]. In 2010, the Chinese government launched 'an action plan for malaria elimination' in the aim to eliminate malaria throughout the country by the end of 2020. Since then, great progress has been made to reduce the morbidity and mortality of malaria [2]. Although there has been no indigenous malaria case in the past endemic areas, the imported cases have become a big public health challenge in China. In 2016, a total of 3317 imported cases were reported in China, accounting for $99.9 \%$ of all [3]. In addition, most of the imported cases were infected with Plasmodium falciparum ( $P$. falciparum).

Artemisinin-based combination therapy (ACT) has been recommended for the treatment of uncomplicated falciparum malaria in nearly all areas as recommended by WHO, since the emergence and spread of multi-drug resistant $P$. falciparum strains [4]. The ACT combines a fast-acting but rapidly-cleared artemisinin derivative with a long-lasting partner drug. Artesunate/amodiaquine (AS-AQ) and artemether/lumefantrine (AL) are the first-line drugs for uncomplicated P. falciparum malaria in Africa. In China, AS-AQ and dihydroartemisinin/ piperaquine (DHA-PPQ) are recommended for uncomplicated P. falciparum infection [5]. The ACT therapy indeed shows a high efficacy, but an emerging ACT resistance has raised serious concern. Since the first report of emergence of $P$. falciparum resistance to artemisinin in 2008 in western Cambodia [6], such resistance has spread to all countries of the Greater Mekong Subregion [7-9]. The presence of resistance to ACT partner drugs has caused treatment failure with DHA-PPQ, AL, etc. [10-12]. Therefore, it is important and necessary to survey the emergence and the distribution of artemisinin and partner drug resistance in order to guide public health measures and rational administration at the level of local government.

It has been widely accepted that $p f c r t$, pfmdr 1 , and K13-propeller are candidate genes for resistance to antimalarial drugs $[10,13,14]$. Single nucleotide polymorphisms (SNPs) have been found in exon 2 of the pfcrt gene at codons 74, 75, and 76, which are associated with resistance of $P$. falciparum to chloroquine (CQ) and amodiaquine (AQ) $[15,16]$. Among them, the K76T mutation is the primary mediator of $C Q$ and AQ resistance, which is always accompanied by M74I and N75E mutations to maintain adequate fitness of the K76T resistant isolates $[10,14]$. Studies on $p f m d r 1$ gene have identified 5 resistance-associated SNPs, of which the N86Y and
Y184F are more common to Asian- and African-derived parasites while S1034C, N1042D, and D1246Y are found more frequently in South America [17]. Experimental evidence indicates that the combination of $86 \mathrm{Y} / 184 \mathrm{Y} /$ $1246 \mathrm{Y}$ which creates the 'YYY' haplotype contributes to the recrudescence and reinfections following AS-AQ or AQ treatment $[18,19]$. The NFD haplotype (86 N/184F/ 1246D) reduces parasite susceptibility to AL, and can be selected by treatment with AL $[18,19]$. Other mutations (S1034C and N1042D) are primarily associated with altered sensitivity to lumefantrine (LMF), mefloquine (MQ), and artemisinin [20].

Clinical artemisinin resistance, which manifests as the delayed parasite clearance, was first reported in Pailin, Western Cambodia in 2009 [6, 21]. This resistance is primarily modulated by mutations in the propeller domain of $P$. falciparum chromosome 13 (K13-propeller) in Southeast Asia, including 5 SNPs (N458Y, Y493H, R539T, I543T, and C580Y) verified so far [22, 23]. The C580Y SNP has also been reported in Africa [22]. Molecular surveillance of K13-propeller polymorphism has been recommended as a complementary tool to evaluate the presence of artemisinin resistance in malaria pandemic countries.

Currently, imported malaria is not only a threat to public health but also has become the most serious challenge for Chinese government to eliminate malaria within years [24]. There have been many studies on imported malaria cases from different areas conducted in China [25-27], but with most of the cases being from Africa, they provided inconsistent results on the drugresistance associated gene polymorphisms and their frequencies. In this study, we set out to evaluate polymorphisms of pfcrt, pfmdr1, and K13-propeller genes in imported falciparum malaria cases from Africa, in order to provide guidance on antimalarial drug administration for the local government of Guizhou Province.

\section{Method \\ Data collection}

Malaria case data were provided by Guizhou Provincial Centre for Disease Control and Prevention. Fifty-five patients who returned from Africa during 2012-2016, diagnosed with malaria initially by microscopy of Giemsa's solution-stained thick and thin blood smears at local hospitals or local County Centres for Disease Control and Prevention, and confirmed at Guizhou Provincial Center for Disease Control and Prevention by microscopic examination and nested PCR, were included in this study [28]. Blood filter papers from each patient were prepared and stored in individual plastic bags at $20{ }^{\circ} \mathrm{C}$ after being air dried for DNA extraction. Malaria parasite species identification was carried out by nested PCR as previously described [28]. All the 55 malaria 
cases were confirmed to be infected with $P$. falciparum without mixed infections. The imported cases were from 15 African countries and were roughly categorized into the West Africa $(n=41$, including Angola, Benin, Cameroon, Republic of the Congo, Democratic Republic of the Congo, Equatorial Guinea, Gabon, Ghana, Liberia, Nigeria, the Republic of Guinea, and Zambia) and the East Africa ( $n=14$, Mozambique, Tanzania, and Uganda)

\section{SNP analysis}

Parasite genomic DNA was extracted from the filter paper blood using a QIAamp DNA mini kit (Qiagen, Valencia, CA, USA) following the manufacturer's instructions. We assessed $P$. falciparum polymorphisms at alleles of $p f c r t$ M74I, N75E, K76T; pfmdr1 N86Y, Y184F, S1034C, N0142D, D1246Y, and the mutation of PF3D7_ 1343700 kelch propeller domain gene (PF13_0238, also called K13-propeller), a molecular marker of artemisinin resistance, using nested PCR amplification followed by sequencing. The primer sequences were all from published literature $[27,29,30]$ and are shown in Table 1.

PCR was performed based on previous publications with minor modification $[27,29,30]$. Briefly, for the 1st round of PCR, $2.0 \mu \mathrm{L}$ genomic DNA template, $12.5 \mu \mathrm{L}$ Premix rTaq, $1.0 \mu \mathrm{L}$ forward primer $(10 \mu \mathrm{M}), 1.0 \mu \mathrm{L}$ reverse primer $\left(10 \mu \mathrm{M}\right.$ ), and $\mathrm{ddH}_{2} \mathrm{O}$ (up to $25.0 \mu \mathrm{L}$ ) were mixed and subjected to the following program: initial denaturation at $95^{\circ} \mathrm{C}$ for $3 \mathrm{~min}$, followed by 35 cycles of $95^{\circ} \mathrm{C}$ for $30 \mathrm{~s}, 52^{\circ} \mathrm{C}$ for $30 \mathrm{~s}$, and $72{ }^{\circ} \mathrm{C}$ for $1 \mathrm{~min}$, and a final extension at $60^{\circ} \mathrm{C}$ for $5 \mathrm{~min}$. For the $2^{\text {nd }}$ round of PCR, $2.0 \mu \mathrm{L}$ products from the 1st round of PCR with $25.0 \mu \mathrm{L}$ Premix rTaq, $1.0 \mu \mathrm{L}$ forward primer $(10 \mu \mathrm{M})$, $1.0 \mu \mathrm{L}$ reverse primer $\left(10 \mu \mathrm{M}\right.$ ), and $\mathrm{ddH}_{2} \mathrm{O}$ (up to $50.0 \mu \mathrm{L}$ ) were mixed and subjected to the following program: initial denaturation at $95^{\circ} \mathrm{C}$ for $3 \mathrm{~min}$, followed by 35 cycles of $95^{\circ} \mathrm{C}$ for $30 \mathrm{~s}, 54{ }^{\circ} \mathrm{C}$ for $30 \mathrm{~s}$, and $72{ }^{\circ} \mathrm{C}$ for $60 \mathrm{~s}$, and a final extension at $72{ }^{\circ} \mathrm{C}$ for $5 \mathrm{~min}$. Five microliters of products from the 2nd round of PCR were analyzed by $1.2 \%$ agarose gel electrophoresis. The major bands were harvested and purified for bi-directional DNA sequencing (Sangon Biotech, Shanghai, China).

\section{Data analysis}

Sequence alignment and analysis were carried out using DNAstar 7.0 software (DNASTAR Inc., Madison, WI, USA). The nucleotide and amino-acid sequences of $p f c r t$, pfmdr1, and K13-propeller from P. falciparum 3D7 strain (Genbank ID: Pf3D7_0523000, Pf3D7_0709000, Pf3D7_1343700) were used as the reference for alignment. Data were imported into Excel to construct database, and were analyzed with Person's Chi square test or Fisher exact test using the SPSS 17.0 software. $P<0.05$ was considered as statistically significant.

Table 1 Primer sequences in this study

\begin{tabular}{|c|c|c|c|c|c|}
\hline Gene & Locus & Round & Primers & Sequence $\left(5^{\prime} \rightarrow 3^{\prime}\right)$ & Amplicons (bp) \\
\hline \multirow[t]{4}{*}{ pfcrt [27] } & $74,75,76$ & $1 \mathrm{st}$ & CRT1-1 & CCGTTAATAATAAATACACGCAG & 537 \\
\hline & & & CRT1-2 & CGGATGTTACAAAACTATAGTTACC & \\
\hline & & 2nd & CRT2-1 & TGTGCTCATGTGTTTAAACTT & 145 \\
\hline & & & CRT2-2 & CAAAACTATAGTTACCAATTTTG & \\
\hline \multirow[t]{12}{*}{ pfmdr1 [29] } & 86,184 & 1 st & MDR1-1F & TTAAATGTTTACCTGCACAACATAGAAAATT & 612 \\
\hline & & & MDR1-1R & СTCCACAATAACTTGCAACAGTTCTTA & \\
\hline & & 2nd & MDR1-2F & TGTATGTGCTGTATTATCAGGA & 526 \\
\hline & & & MDR1-2R & CTCTTCTATAATGGACATGGTA & \\
\hline & 1034,1042 & $1 s t$ & $1042-A$ & GTCGAAAAGACTATGAAACGTAGA & 350 \\
\hline & & & $1042-C$ & CTCAAATGATAATTTTGCAT & \\
\hline & & 2nd & $1042-B$ & GATCCAAGTITITIAATACA & \\
\hline & & & $1042-C$ & CTCAAATGATAATTITGCAT & \\
\hline & 1246 & $1 s t$ & $1246-A$ & GTGGAAAATCAACTITTATGA & 410 \\
\hline & & & $1246-B$ & TTAGGTTCTCTTAATAATGCT & \\
\hline & & 2nd & $1246-C$ & GACTTGAAAAATGATCACATT & \\
\hline & & & $1246-D$ & GTCCACCTGATATGCTITT & \\
\hline \multirow[t]{4}{*}{ K13-propeller [30] } & & $1 s t$ & K13-1-1 & CGGAGTGACCAAATCTGGGA & 2063 \\
\hline & & & K13-1-2 & GGGAATCTGGTGGTAACAGC & \\
\hline & & 2nd & K13-2-1 & GCCTTGTTGAAAGAAGCAGA & 849 \\
\hline & & & $\mathrm{K} 13-2-2$ & GCCAAGCTGCCATTCATTTG & \\
\hline
\end{tabular}


Table 2 Geographic distribution of the imported falciparum malaria cases from Africa in Guizhou Province during 2012-2016

\begin{tabular}{lll}
\hline geographical division & country name & cases \\
\hline West Africa & Angola & 4 \\
& Benin & 1 \\
& Cameroon & 3 \\
& Democratic Republic of the Congo & 4 \\
& Equatorial Guinea & 1 \\
& Gabon & 1 \\
& Ghana & 1 \\
& Liberia & 14 \\
& Nigeria & 6 \\
& Republic of the Congo & 2 \\
& the Republic of Guinea & 3 \\
& Zambia & 1 \\
East Africa & Mozambique & 1 \\
& Uganda & 11 \\
& Tanzania & 2 \\
\hline
\end{tabular}

\section{Results}

\section{Demographics of patients}

A total of 55 filter paper blood samples were collected from imported falciparum malaria cases who returned from 15 African countries to Guizhou Province during 2012-2016, with a male/female ratio of 12.75:1 (51:4) and mean age of $37.6 \pm 9.31$ years old (range: $25-59)$. In addition, $74.55 \%(n=41)$ of the imported cases were from West Africa, and $25.45 \%(n=14)$ of them were from East Africa (See Table 2).

\section{SNPs and haplotypes of the pfcrt gene}

PCR products (145-bp) of the pfcrt gene covering codons 74-76 were sequenced in $96.4 \%$ (53/55) of the cases. The prevalence of K76T mutation was $56.6 \%$ (30/ 53), and the other two mutations N75E and M74I had a total prevalence of $54.7 \%$ (29/53). The proportion of pfcrt haplotype IET was significantly different between cases from East Africa and West Africa, while the MNT proportion did not differ significantly. The detail information of the mutations is shown in Table 3 and Fig. S1.

\section{SNPs and haplotypes of the pfmdr1 gene}

pfindr1 genotyping was successfully performed in $98.2 \%$ $(54 / 55)$ of cases for codons 86, 184, 1034, 1042, and 1246. No mutations were identified at codons 1034 and 1042. The $184 \mathrm{~F}$ mutation was the most-frequent nonsynonymous mutation $(72.2 \%, 39 / 54)$ ) among all the mutations, comprising a prevalence of 85.7 and $62.5 \%$ in cases from East Africa and West Africa, respectively, with no significant difference between them $(P=0.407)$. The $86 \mathrm{Y}$ mutation was detected in $14.3 \%$ of East Africa and $25 \%$ of West Africa isolates, with an overall prevalence of $22.2 \%$. The $1246 \mathrm{Y}$ mutation was not detected in East Africa, but in $7.5 \%$ of West Africa isolates, with a total prevalence of $5.6 \%$. There were 5 mutation haplotypes for $p f m d r 1$, including NFD, YFD, YFY, YYD, and NYY, with prevalence of 53.7, 14.8, 3.7, 3.7, and 1.9\%, respectively. None of the 5 haplotypes had significant difference between East Africa and West Africa. Detailed information of the mutations is shown in Table 4, Fig. S2, and Fig. S3.

\section{Combined haplotypes of pfort and pfmdr 1}

Both $p f c r t$ gene and $p f m d r 1$ gene were genotyped successfully in 52 cases and the combined haplotypes are summarized in Table 5. They had a total of 10 combined haplotypes, predominated by IETNFD and MNKNFD with prevalence of 28.8 and $26.9 \%$, respectively.

\section{SNPs of K13-propeller}

To investigate the K13-propeller SNP, an 849-bp PCR product was successfully sequenced in $90.9 \%$ (50/55) of the samples. Five SNPs were observed in 7 samples, including 3 nonsynonymous mutations and 2 synonymous mutations (Table 6 and Fig. 1). The three nonsynonymous mutations were S459T, C469F, and V692L, with equal prevalence of $2.0 \%(n=1)$. The two synonymous

Table 3 Prevalence of SNPs and mutation haplotypes of pfcrt gene

\begin{tabular}{|c|c|c|c|c|c|}
\hline $\begin{array}{l}\text { SNPs / mutation } \\
\text { haplotypes }\end{array}$ & $\begin{array}{l}\text { Number of isolates and total } \\
\text { prevalence }(N=53) n(\%)\end{array}$ & $95 \% \mathrm{Cl}$ & $\begin{array}{l}\text { Number of isolates from East } \\
\text { Africa }(N=13) n(\%)\end{array}$ & $\begin{array}{l}\text { Number of isolates from West } \\
\text { Africa }(N=40) n(\%)\end{array}$ & $\begin{array}{l}P \text { - } \\
\text { value }\end{array}$ \\
\hline$\overline{\mathrm{K} 76 \mathrm{~T}}$ & $30(56.6)$ & $\begin{array}{l}(0.4269, \\
0.6938)\end{array}$ & $3(23.0)$ & $27(67.5)$ & 0.005 \\
\hline N75E & $29(54.7)$ & $\begin{array}{l}(0.4141 \\
0.6805)\end{array}$ & $3(23.0)$ & $26(65.0)$ & 0.008 \\
\hline M74I & $29(54.7)$ & $\begin{array}{l}(0.4141 \\
0.6805)\end{array}$ & $3(23.0)$ & $26(65.0)$ & 0.008 \\
\hline IET & $29(54.7)$ & $\begin{array}{l}(0.4141 \\
0.6805)\end{array}$ & $3(23.0)$ & $26(65.0)$ & 0.008 \\
\hline MNT & $1(1.9)$ & $\begin{array}{l}(-0.0178 \\
0.0555)\end{array}$ & 0 & $1(2.5)$ & 0.57 \\
\hline
\end{tabular}


Table 4 Prevalence of SNPs and haplotypes of pfmdr1 gene

\begin{tabular}{|c|c|c|c|c|c|}
\hline $\begin{array}{l}\text { SNPs / mutation } \\
\text { haplotypes }\end{array}$ & $\begin{array}{l}\text { Number of isolates }(N= \\
54) n(\%)\end{array}$ & $95 \% \mathrm{Cl}$ & $\begin{array}{l}\text { Number of isolates from East Africa } \\
(N=14) n(\%)\end{array}$ & $\begin{array}{l}\text { Number of isolates from West Africa } \\
(N=40) n(\%)\end{array}$ & $\begin{array}{l}P \text { - } \\
\text { value }\end{array}$ \\
\hline N86Y & $12(22.2)$ & $\begin{array}{l}(0.111, \\
0.333)\end{array}$ & $2(14.3)$ & $10(25.0)$ & 0.407 \\
\hline Y184F & $39(72.2)$ & $\begin{array}{l}(0.603, \\
0.841)\end{array}$ & $13(92.9)$ & $26(65.0)$ & 0.107 \\
\hline D1246Y & $3(5.6)$ & $\begin{array}{l}(-0.005 \\
0.117)\end{array}$ & 0 & $3(7.5)$ & 0.292 \\
\hline NFD & $29(53.7)$ & $\begin{array}{l}(0.404, \\
0.669)\end{array}$ & 11 (78.6) & $18(45.0)$ & 0.226 \\
\hline YFD & $8(14.8)$ & $\begin{array}{l}(0.050 \\
0.238)\end{array}$ & $2(14.3)$ & $6(15.0)$ & 0.948 \\
\hline YFY & $2(3.7)$ & $\begin{array}{l}(-0.013 \\
0.087)\end{array}$ & 0 & $2(5.0)$ & 0.394 \\
\hline YYD & $2(3.7)$ & $\begin{array}{l}(-0.013 \\
0.087)\end{array}$ & 0 & $2(5.0)$ & 0.394 \\
\hline NYY & $1(1.9)$ & $\begin{array}{l}(0.001 \\
0.037)\end{array}$ & 0 & $1(2.5)$ & 0.55 \\
\hline
\end{tabular}

mutations were $\mathrm{R} 471 \mathrm{R}$ and $\mathrm{V} 589 \mathrm{~V}$, with prevalence of $6.0 \%(n=3)$ and $2.0 \%(n=1)$, respectively.

\section{Discussion}

Guizhou Province is located in the southwest of China and was once one of the provinces with greatest malaria burden. No indigenous cases have been reported since 2012 after a long-term strategy on malaria control in Guizhou [28]. However, imported malaria cases, especially falciparum malaria, have become the biggest risk that hinders malaria control and elimination in Guizhou.

In this study, we investigated the drug resistanceassociated mutations of $P$. falciparum from imported cases from Africa in Guizhou Province during 20122016. We found that the prevalence of K76T mutation (56.6\%) was highest among the three mutations of pfcrt.

Table 5 Prevalence of correlated pfmdr1-pfcrt haplotypes ( $N=$

\begin{tabular}{|c|c|c|c|c|c|c|c|}
\hline \multicolumn{3}{|c|}{ Pfcrt } & \multicolumn{3}{|c|}{ pfmdr1 } & \multirow{2}{*}{$\begin{array}{l}\text { Number } \\
\text { of } \\
\text { isolates } \\
(\%)\end{array}$} & \multirow[t]{2}{*}{$95 \% \mathrm{Cl}$} \\
\hline 74 & 75 & 76 & 86 & 184 & 1246 & & \\
\hline$M$ & $N$ & K & $\mathrm{N}$ & Y & $\mathrm{D}$ & $6(11.5)$ & $(0.028548,0.202222)$ \\
\hline M & N & K & N & $\mathrm{F}$ & $\mathrm{D}$ & $14(26.9)$ & $(0.148670,0.389792)$ \\
\hline M & N & K & Y & Y & $\mathrm{D}$ & $1(1.9)$ & $(-0.0180973,0.056559)$ \\
\hline M & N & K & Y & $\mathrm{F}$ & $\mathrm{D}$ & $2(3.8)$ & $(-0.013808,0.090732)$ \\
\hline । & $E$ & $\mathrm{~T}$ & $\mathrm{~N}$ & Y & $\mathrm{D}$ & $5(9.6)$ & $(0.016026,0.176282)$ \\
\hline । & $E$ & $\mathrm{~T}$ & N & $\mathrm{F}$ & $\mathrm{D}$ & $15(28.8)$ & $(0.165322,0.411602)$ \\
\hline । & $E$ & $\mathrm{~T}$ & Y & $\mathrm{F}$ & $\mathrm{D}$ & $5(9.6)$ & $(0.016026,0.176282)$ \\
\hline । & $E$ & $\mathrm{~T}$ & Y & $\mathrm{F}$ & Y & $2(3.8)$ & $(-0.013808,0.090732)$ \\
\hline । & $E$ & $\mathrm{~T}$ & $\mathrm{~N}$ & Y & Y & $1(1.9)$ & $(-0.0180973,0.056559$ \\
\hline M & N & $\mathrm{T}$ & N & Y & $\mathrm{D}$ & $1(1.9)$ & $(-0.0180973,0.056559)$ \\
\hline
\end{tabular}

The K76T mutation has been confirmed as a key marker of CQ resistance by epidemiological, reverse genetic, and heterologous expression studies [31, 32], therefore CQ is not preferred for treatment of falciparum malaria cases with $p f c r t$ K76T mutation. We also detected two mutant haplotypes of $p f c r t$ gene (IET and MNT), with the haplotype IET (54.7\%) more prevalent than the other, and significantly higher than the average level $(30 \%)$ in Africa in a recent study [33]. CQ was the first-line antimalarial drug in Africa during 1998-2008. Although previous studies have illustrated partial recovery of CQ sensitivity after CQ withdrawal $[34,35]$, a report has pointed out that the return of CQ-susceptible malaria to the entire African region is not a synchronous process [25]. The high prevalence of $p f c r t$ K76T mutation in this study may be related to the special population (imported malaria) and the limited sample size. Here we also found a significant difference in the prevalence of IET haplotype between East Africa (23\%) and West Africa (65\%). The CQ resistance was initially identified in East Africa in the late 1970s, and countries in this area were the first to change their front-line treatments from CQ to other antimalarial drugs $[36,37]$. In this study, only one case was detected the MNT haplotype, which is consistent with the fact that MNT is more common in South America and some Asian countries, while rarely reported in Africa [38].

The pfmdr1 with the N86Y and D1246Y mutation can confer resistance to a wide range of first-line antimalarial drugs in vivo and in vitro such as CQ and AS-AQ, especially for the N86Y [39]. The Y184F mutation is more popular in Africa, which has only a weak association with antimalarial effectiveness in vivo and in vitro depending on the status of residue 86 [33, 40]. In this study, we detected 3 SNPs (N86Y, Y184F, and D1246Y) 
Table 6 Polymorphisms observed in the K13-propeller in P. falciparum isolates

\begin{tabular}{|c|c|c|c|c|c|c|}
\hline $\begin{array}{l}\text { Codon } \\
\text { position }\end{array}$ & $\begin{array}{l}\text { Amino acid } \\
\text { reference }\end{array}$ & $\begin{array}{l}\text { Nucleotide } \\
\text { reference }\end{array}$ & $\begin{array}{l}\text { Amino acid } \\
\text { mutation }\end{array}$ & $\begin{array}{l}\text { Nucleotide } \\
\text { mutation }\end{array}$ & $\begin{array}{l}\text { Number of isolates } \\
\text { (\%) }\end{array}$ & Original country \\
\hline 459 & $S$ & TCG & $\mathrm{T}$ & ACG & $1(2)$ & Tanzania \\
\hline 469 & C & TGC & $\mathrm{F}$ & $\pi \mathrm{C}$ & $1(2)$ & $\begin{array}{l}\text { Democratic Republic of the } \\
\text { Congo }\end{array}$ \\
\hline 471 & $\mathrm{R}$ & CGT & $\mathrm{R}$ & CGC & $3(6)$ & Angola (2), Gabon (1) \\
\hline 589 & V & GTC & V & GTG & $1(2)$ & Benin \\
\hline 692 & V & GTT & L & $\mathrm{CT}$ & $1(2)$ & Liberia \\
\hline 696 & A & GCC & v & GTC & $1(2)$ & Nigeria \\
\hline
\end{tabular}

in imported falciparum malaria cases, of which Y184F (72.2\%) was the most prevalent, while N86Y and D1246Y being detected in only 22.2 and $5.6 \%$. Currently, many studies have shown that N86Y increases parasite susceptibility to LMF, MQ, and DHA, and augments resistance to md-AQ and CQ [41, 42]. When parasites are engineered to express wild-type N86, they demonstrate a higher drug $\mathrm{IC}_{50}$ (inhibitory concentration $50 \%$ ) value for MQ and LMF, compared with the mutant N86Y residue [33]. Consistently, other studies have reported that the N86 allele predominates in recurrent infections following AL treatment $[17,19]$. And this has been verified by a meta-analysis of 31 clinical trials [40]. Therefore, the low prevalence of $\mathrm{N} 86 \mathrm{Y}$ in this study may indicate a decreased parasite susceptibility to AL, MQ, and DHA. The high frequency of Y184F shows an increased resistance to PPQ when paired with N86. Among the 5 mutation haplotypes, the NFD haplotype had the highest prevalence of $53.7 \%$. A previous study has shown a significant resistance to PPQ in NFD parasites with IET

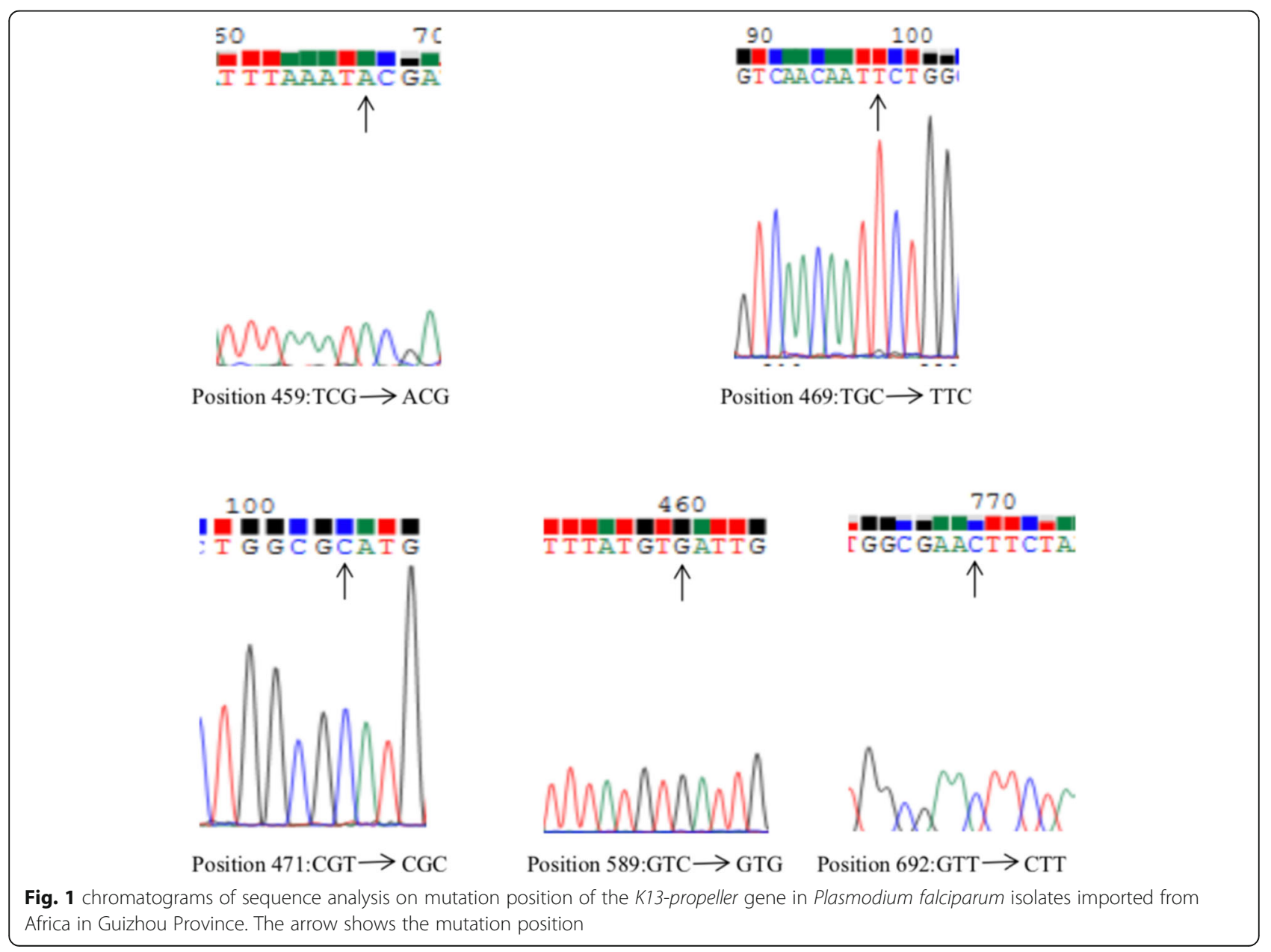


background in Southeast Asia [33, 40]. Furthermore, the parasites expressing the combination haplotype NFDIET were predominant in this study. Therefore, these cases should be monitored when AL and DHA-PPQ are used as the first-line anti-malaria drugs.

To date, more than 200 SNPs have been detected in the K13-propeller gene of $P$. falciparum isolates worldwide, of which 5 SNPs are validated to be resistance mutations by in vitro and in vivo data and 26 SNPs are candidate resistance mutations correlated with delayed parasite clearance [22]. In this study, we identified 5 SNPs in 7 isolates, of which 3 were nonsynonymous mutations and 2 were synonymous mutations. Among the 3 nonsynonymous mutations, only a candidate K13 resistance mutation, C469F, was identified for the first time in a P. falciparum isolate from Democratic Republic of the Congo with the prevalence of $2.0 \%$. C469F and C469Y are two types of mutation only found in Southeast Asia with low prevalence that are candidate mutations to be correlated with delayed parasite clearance [22, 43]. Therefore, the first detection of C469F mutation in imported cases from Africa raises concerns about the emergence of artemisinin resistance in Africa. S459T was identified in a P. falciparum isolate of Tanzania with the prevalence of $2.0 \%$. S459L has also been reported in both Sub-Saharan Africa and Southeast Asia [23]. Two synonymous mutations R471R and V589V were identified with prevalence of 6.0 and $2.0 \%$ respectively. The R471R mutation has also been identified in P. falciparum isolates from Angola by Yang et al. [44]. The low-frequency mutations in K13 propeller gene have been detected widely in many studies in Africa. However, the candidate resistance mutation found for the first time increases the risk of emergence and dissemination of artemisinin resistance in Africa.

\section{Conclusions}

The present study demonstrates the current status of antimalarial drug resistance in imported falciparum malaria cases in Guizhou Province, China. CQ resistance pressure still exists. AL and DHA-PPQ are not recommended for use in imported falciparum malaria cases in Guizhou Province. There is a potential risk of artemisinin resistance in Africa since a candidate $\mathrm{K} 13$ resistance mutation has been found. Based on the current results, it is important and imperative to continue a molecular surveillance of anti-malarial drugs for imported malaria cases, which will be helpful to rationalize drug guidance for local authorities in China.

\section{Supplementary information}

Supplementary information accompanies this paper at https://doi.org/10. 1186/s12879-020-05228-8.

Additional file 1: Figure S1. Nucleotide sequences alignment of pfcr K76T of imported Plasmodim falciparum isolates from Africa in Guizhou Province. The detected locus is highlighted in red, and the sequence polymorphism is marked in yellow.
Additional file 2: Figure S2. Nucleotide sequences alignment of pfmdr1 N86Y, Y184F of imported Plasmodim falciparum isolates from Africa in Guizhou Province. The detected locus is highlighted in red, and the sequence polymorphism is marked in yellow.

Additional file 3: Figure S3. Nucleotide sequences alignment of pfmdr1 D1246Y of imported Plasmodim falciparum isolates from Africa in Guizhou Province. The detected locus is highlighted in red, and the sequence polymorphism is marked in yellow.

\section{Abbreviations}

ACT: Artemisinin-based combination therapy; WHO: World Health Organization; AS-AQ: Artesunate/amodiaquine; AL: Artemether/lumefantrine; DHA-PPQ: Dihydroartemisinin/piperaquine; SNPs: Single nucleotide polymorphisms

\section{Acknowledgements}

Not applicable.

\section{Authors' contributions}

WJH designed the whole study, genetic analysis and wrote the manuscript. SDY and WZY performed the study. SDY and LLD provided the general information, the filter paper blood samples and the microscopic results. HYT provided the molecular diagnostic results of malaria. LQG analyzed the data. ZK involved in the data analysis and revised the manuscript. AD involved in designing the whole study and the patient data collected. All authors read and approved the final manuscript.

\section{Funding}

The study was supported by the Project of Basic Science and Technology Platform in Guizhou Province, China (No. 2012[4006]). The funder had no role in study design, data collection and analysis, decision to publish, or preparation of the manuscript.

\section{Availability of data and materials}

The sequence alignment information is provided in Supplementary figures. The datasets generated during the study are not publicly available due to the personal information but are available from the corresponding author on reasonable request.

\section{Ethics approval and consent to participate}

The ethics committees of Guizhou Provincial Center for Disease Control and Prevention (ECGZCDC) reviewed and approved the study. The consent to participate was waived with the approval of the ECGZCDC because of the following reasons: 1. No personal information was included. 2. The study will be beneficial to public health and do no harm to the participants. 3. The blood filter paper samples were collected for the species identification and polymorphism of anti-malarial drugs genes by PCR according to the national regulations and the data were used for this study.

Consent for publication

Not applicable.

\section{Competing interests}

The authors declare that they have no competing interests.

\section{Author details}

'Key Laboratory of Environmental Pollution Monitoring and Disease Control, Ministry of Education, Guizhou Medical University; Department of Parasitology; Provincial Key Laboratory of Modern Pathogen Biology, Guizhou Medical University, Guiyang 550025, China. ${ }^{2}$ Guizhou Provincial Center for Disease Control and Prevention, Guiyang 550004, China.

Received: 20 February 2019 Accepted: 3 July 2020

Published online: 16 July 2020

\section{References}

1. WHO. World malaria report 2017. Geneva: World Health Organization; 2017.

2. China action plan for malaria elimination. In. Available at http://www.moh. gov.cn/publicfiles/business/htmlfiles/mohibyfkz//s3593/201005/47529.htm. 2010; 2010.(in Chinese). 
3. Zhang L, Feng J, Zhang S, Jiang S, Xia Z, Zhou S. Malaria situation in the People's Republic of China in 2016(in Chinese). Chin J Parasitol Parasi Dis. 2017;35(6):515-9.

4. WHO. Guidelines for the treatment of malaria. 3rd ed: WHO; 2015. Available at http://www.who.int/malaria/publications/atoz/9789241549127/en/.

5. China NHAF. Technical regulations for application of antimalarials (in Chinese). In: (WS/T 485-2016). Edited by Standard TPSR; 2016.

6. Noedl H, Se Y, Schaecher K, Smith B, Socheat D, Fukuda M. Evidence of artemisinin-resistant malaria in western Cambodia. N Engl J Med. 2008;359: 2619-20.

7. Huang F, Takala-Harrison S, Jacob CG, Liu H, Sun X, Yang H, Nyunt MM, Adams M, Zhou S, Xia Z, et al. A single mutation in K13 predominates in southern China and is associated with delayed clearance of Plasmodium falciparum following artemisinin treatment. J Infect Dis. 2015;212(10):1629-35.

8. Ashley EA, Dhorda M, Fairhurst RM, Amaratunga C, Lim P, Suon S, Sreng S, Anderson JM, Mao S, Sam B, et al. Spread of artemisinin resistance in Plasmodium falciparum malaria. N Engl J Med. 2014;371(5):411-23.

9. Amaratunga C, Sreng S, Suon S, Phelps ES, Stepniewska K, Lim P, Zhou C, Mao S, Anderson JM, Lindegardh N, et al. Artemisinin-resistant Plasmodium falciparum in Pursat province, western Cambodia: a parasite clearance rate study. Lancet Infect Dis. 2012;12(11):851-8.

10. Menard D, Dondorp A. Antimalarial drug resistance: a threat to malaria elimination. CSH Perspect Med. 2017;7(7):a25619.

11. Leang R, Taylor WR, Bouth DM, Song L, Tarning J, Char MC, Kim S, Witkowski B, Duru V, Domergue A, et al. Evidence of Plasmodium falciparum malaria multidrug resistance to Artemisinin and Piperaquine in Western Cambodia: Dihydroartemisinin-Piperaquine open-label multicenter clinical assessment. Antimicrob Agents Chemother. 2015;59(8):4719-26.

12. Leang R, Barrette A, Bouth DM, Menard D, Abdur R, Duong S, Ringwald P. Efficacy of dihydroartemisinin-piperaquine for treatment of uncomplicated Plasmodium falciparum and Plasmodium vivax in Cambodia, 2008 to 2010. Antimicrob Agents Chemother. 2013;57(2):818-26.

13. Takala-Harrison S, Laufer MK. Antimalarial drug resistance in Africa: key lessons for the future. AnnNy Acad Sci. 2015;1342(1):62-7.

14. Rosenthal PJ, Rathod PK, Ndiaye D, Mharakurwa S, Cui L. Antimalarial drug resistance: literature review and activities and findings of the ICEMR network. Am J Trop Med Hyg. 2015;93(3_Suppl):57-68.

15. Awasthi G, Satya G, Das A. Pfcrt haplotypes and the evolutionary history of chloroquineresistant Plasmodium falciparum. Mem Inst Oswaldo Cruz. 2012;107:129-34.

16. Awasthi G, Prasad G, Das A. Population genetic analyses of pfcrt haplotypes reveal the evolutionary history of chloroquine resistant malaria in India. Int J Parasitol. 2011;41:705-9.

17. Foote SJ, Kyle DE, Martin RK, Oduola AM, Forsyth K, Kemp DJ, Cowman AF. Several alleles of the multidrug-resistance gene are closely linked to chloroquine resistance in Plasmodium falciparum. NATURE. 1990;345(6272):255-8.

18. Otienoburu SD, Maïga-Ascofaré $O$, Schramm B, Jullien V, Jones JJ, Zolia YM, Houzé P, Ashley EA, Kiechel J, Guérin PJ, et al. Selection of Plasmodium falciparum pfcrt and pfmdr1 polymorphisms after treatment with artesunate-amodiaquine fixed dose combination or artemetherlumefantrine in Liberia. Malar J. 2016;15(1):452.

19. Dokomajilar C, Nsobya S, Greenhouse B, Rosenthal P, Dorsey G. Selection of Plasmodium falciparum pfmdr1 alleles following therapy with artemether-lumefantrine in an area of Uganda where malaria is highly endemic. Antimicrob Agents Chemother. 2006;50:1893-5.

20. Gil JP. Krishna S: pfmdr1 (Plasmodium falciparum multidrug drug resistance gene 1): a pivotal factor in malaria resistance to artemisinin combination therapies. Expert Rev Anti-Infect Ther. 2017;15(6):527-43.

21. Dondorp A, Nosten F, Yi P, Das D, Phyo A, Tarning J, Lwin K, Ariey F, Hanpithakpong $W$, Lee $S$, et al. Artemisinin resistance in Plasmodium falciparum malaria. N Engl J Med. 2009;361:455-67.

22. WHO: Artemisinin and artemisinin-based combination therapy resistance. 2017

23. Straimer J, Gnadig NF, Witkowski B, Amaratunga C, Duru V, Ramadani AP, Dacheux M, Khim N, Zhang L, Lam S, et al. Drug resistance. K13-propeller mutations confer artemisinin resistance in Plasmodium falciparum clinical isolates. SCIENCE. 2015;347(6220):428-31.

24. Cao J, Liu Y, Cao Y, Zhu G, Zhou S. Sustained challenge to malaria elimination in China: imported malaria (in Chinese). Chin J Parasitol Parasi Dis. 2018;36(2):93-6.

25. Zhang T, Xu X, Jiang J, Yu C, Tian C, Li W. Surveillance of antimalarial resistance molecular markers in imported Plasmodium falciparum malaria cases in Anhui, China, 2012-2016. Am J Trop Med Hyg. 2018;98(4):1132-6.
26. Lu F, Culleton R, Zhang M, Ramaprasad A, von Seidlein L, Zhou H, Zhu G, Tang J, Liu Y, Wang W, et al. Emergence of indigenous Artemisinin-resistant Plasmodium falciparum in Africa. N Engl J Med. 2017;376(10):991-3.

27. Zhou R, Zhang H, Yang C, Liu Y, Zhao Y, Li S, Qian D, Xu B. Molecular mutation profile of pfert in Plasmodium falciparum isolates imported from Africa in Henan province. Malar J. 2016;15(1). https://doi.org/10.1186/s12936-016-1306-6.

28. She D, Wu J, Lu L, Huang Y, Geng Y, Zhang N. Evaluation of the testing ability of city/prefecture-level malaria laboratories in Guizhou Province during 2014-2016(in Chinese). Chin J Parasitol Parasi Dis. 2017;35(5):466-70.

29. Jia XS, Zhou SM, Xu MX, Yang Y, Wu K. Mutations of Plasmodium falciparum multidrug resistance 1 gene in imported Plasmodium falciparums in Wuhan (in Chinese). Chin J Parasitol Parasi Dis. 2016;06:489-92.

30. Torrentino-Madamet $M$, Collet $L$, Lepère JF, Benoit N, Amalvict R, Ménard $D$, Pradines B. K13-propeller polymorphisms in Plasmodium falciparum isolates from patients in Mayotte in 2013 and 2014. Antimicrob Agents Ch. 2015; 59(12):7878-81.

31. Ecker A, Lehane AM, Clain J, Fidock DA. PfCRT and its role in antimalarial drug resistance. Trends Parasit. 2012;28(11):504-14.

32. Djimde A, Doumbo OK, Cortese JF, Kayentao K, Doumbo S, Diourte Y, Coulibaly D, Dicko A, Su XZ, Nomura T, et al. A molecular marker for chloroquine-resistant falciparum malaria. N Engl J Med. 2001;344(4):257-63.

33. Veiga MI, Dhingra SK, Henrich PP, Straimer J, Gnädig N, Uhlemann A, Martin RE, Lehane AM, Fidock DA. Globally prevalent PfMDR1 mutations modulate Plasmodium falciparum susceptibility to artemisinin-based combination therapies. Nat Commun. 2016;7:11553.

34. Frosch AE, Laufer MK, Mathanga DP, Takala-Harrison S, Skarbinski J, Claassen CW, Dzinjalamala FK, Plowe CV. Return of widespread chloroquine-sensitive Plasmodium falciparum to Malawi. J Infect Dis. 2014;210(7):1110-4.

35. Flegg J, Metcalf C, Gharbi M, Venkatesan M, Shewchuk T, Hopkins SC, Guerin P. Trends in antimalarial drug use in Africa. Am J Trop Med Hyg. 2013;89:857-65.

36. Kihamia CM, Gill HS. Chloroquine-resistant falciparum malaria in semiimmune African Tanzaniana. LANCET. 1982;2(8288):43.

37. Fogh S, Jepsen S, Effersoe P. Chloroquine-resistant Plasmodium falciparum malaria in Kenya. Trans R Soc Trop Med Hyg. 1979;73(2):228-9.

38. Sa JM, Twu O. Protecting the malaria drug arsenal: halting the rise and spread of amodiaquine resistance by monitoring the PfCRT SVMNT type. Malar J. 2010;9:374. https://doi.org/10.1186/1475-2875-9-374.

39. Reed MB, Saliba KJ, Caruana SR, Kirk K, Cowman AF. Pgh1 modulates sensitivity and resistance to multiple antimalarials in Plasmodium falciparum. NATURE. 2000;403(6772):906-9.

40. Picot S, Olliaro P, de Monbrison F, Bienvenu AL, Price RN, Ringwald P. A systematic review and meta-analysis of evidence for correlation between molecular markers of parasite resistance and treatment outcome in falciparum malaria. Malar J. 2009;8:89. https://doi.org/10.1186/1475-2875-8-89.

41. Malmberg M, Ferreira PE, Tarning J, Ursing J, Ngasala B, Bjorkman A, Martensson A, Gil JP. Plasmodium falciparum drug resistance phenotype as assessed by patient antimalarial drug levels and its association with pfmdr1 polymorphisms. J Infect Dis. 2013;207(5):842-7.

42. Dippmann AK, Bienzle U, Harms G. Mockenhaupt FP: pfmdr1 mutations in imported African Plasmodium falciparum isolates. Trans R Soc Trop Med Hyg. 2008;102(11):1148-50.

43. Fairhurst RM, Dondorp AM. Artemisinin-Resistant Plasmodium falciparum Malaria. Microbiol Spectr. 2016;4(3). https://doi.org/10.1128/microbiolspec El10-0013-2016.

44. Yang C, Zhang H, Zhou R, Qian D, Liu Y, Zhao Y, Li S, Xu B. Polymorphisms of Plasmodium falciparum k13-propeller gene among migrant workers returning to Henan Province, China from Africa. BMC Infect Dis. 2017;17(1):560.

\section{Publisher's Note}

Springer Nature remains neutral with regard to jurisdictional claims in published maps and institutional affiliations. 